\section{Evaluating Florida Homeowner Response to Smart Irrigation Controllers}

\author{
Maria C. Morera ${ }^{1,6}$, Paul F. Monaghan ${ }^{2}$, Michael D. Dukes³, \\ Ondine Wells ${ }^{4}$, and Stacia L. Davis ${ }^{5}$
}

AdDitional INDEX wORDs. ET, SMS, adoption, water conservation, extension

SUMMARY. Smart irrigation controllers are capable of substantially decreasing landscape water applications under residential high water-use conditions in Florida. Their implementation has been incentivized by governmental agencies and water utilities in an effort to reduce public-supply water demand and conserve water resources. However, the bulk of the research on smart controllers for urban landscapes has focused on performance dimensions. To successfully promote them, feedback from end-users is critical. This paper provides an evaluation of homeowner response to evapotranspiration (ET)-based and soil moisture sensor (SMS)-based smart controllers installed as part of a pilot project conducted in Orange County, FL. The objectives of the study were to collect demographic information, assess conservation attitudes and irrigation system knowledge, and gather feedback on the use of smart controllers from the pilot project's residential cooperators. Data were collected through an online survey and analyzed using relative frequency distributions, text analysis, independent means $t$ tests, and logistic regression. Results indicated that a majority of survey participants were satisfied with their controllers and planned to continue using them. Both ET and SMS controllers were consistently praised for saving money and irrigating efficiently. However, the likelihood that participants would continue using their controllers after the completion of the project was only significantly predicted by their levels of technical knowledge regarding the workings of the devices and whether they had experienced any challenges operating them. Efforts to promote both initial and long-term adoption may be most effective by emphasizing the economic benefits of investing in smart irrigation controllers and by disseminating best management practices that facilitate their understanding and successful operation.

$\mathrm{O}$ ver the last 10 years, Florida has repeatedly ranked as one of the nation's largest users of groundwater (Hutson et al., 2004; Kenny et al., 2009; Marella, 2014;

This research was supported in part by Orange County Utilities, the Water Research Foundation, St. John's River Water Management District, and the South Florida Water Management District. Additional support was provided by the University of Florida Institute of Food and Agricultural Sciences Center for Landscape Conservation and Ecology.

${ }^{1}$ Department of Agricultural Education and Communication, University of Florida Institute of Food and Agricultural Sciences, 305 Rolfs Hall, P.O. Box 110540, Gainesville, FL 32611

${ }^{2}$ Department of Agricultural Education and Communication and Center for Landscape Conservation and Ecology, University of Florida Institute of Food and Agricultural Sciences, 305 Rolfs Hall, P.O. Box 110540 , Gainesville, FL 32611

${ }^{3}$ Department of Agricultural and Biological Engineering and Center for Landscape Conservation and Ecology, University of Florida Institute of Food and Agricultural Sciences, 205 Frazier Rogers Hall, P.O. Box 110570, Gainesville, FL 32611

${ }^{4}$ School of Natural Resources and Environment, University of Florida, 103 Black Hall, P.O. Box 116455, Gainesville, FL 32611

${ }^{5}$ Red River Research Station, Louisiana State University AgCenter, 262 Research Station Drive, Bossier City, LA 71112

${ }^{6}$ Corresponding author. E-mail: mmorera@ufl.edu.
Maupin et al., 2014). In 2006, three of the state's five water management districts jointly concluded that traditional groundwater sources may be insufficient to meet future public water supply demands (St. Johns River Water Management District et al., 2008). The population served by Florida's public water systems has more than doubled since 1980 and, in 2010 , public-supply water demand exceeded agricultural demand [Florida Department of Environmental Protection (FDEP), 2014; Maupin et al., 2014]. Residential outdoor water use largely accounts for public water demand (Dukes et al., 2008; Mayer et al., 1999; St. Hilaire et al., 2008). In central Florida, irrigation can make up as much as two-thirds of residential water use (Haley et al., 2007). In response, research efforts have explored the resource conservation potential of irrigation controllers that optimize water use in urban landscapes (Cárdenas-Lailhacar and Dukes, 2012; Cárdenas-Lailhacar Davis et al., 2009; Dukes, 2012; et al., 2008; Davis and Dukes, 2012;
McCready et al., 2009). Defined by the Irrigation Association (IA) as "smart" for their ability to automatically make irrigation schedule adjustments based on site conditions (IA, 2007), smart irrigation controllers are capable of substantially decreasing water applications under residential high water-use conditions in Florida (Cárdenas-Lailhacar and Dukes, 2012; Davis and Dukes, 2012). The use of smart controllers has been promoted by water utilities and incentivized through Florida legislation (Dukes, 2012; Mutchek and Williams, 2010). However, no study to date has assessed Florida homeowner response to smart controllers.

\section{Conceptual framework}

Smart controllers "automatically adjust the frequency of irrigation or the run time or number of cycles based on current growing conditions influenced by the weather, including rainfall" [IA and American Society of Irrigation Consultants (ASIC), 2014]. For example, using signal-based meteorological data, a pre-programmed water-use curve, or on-site weather measurements, evapotranspiration-based smart controllers adjust irrigation run times or watering days according to climate throughout the year (Dukes, 2009; Dukes et al., 2009). Similarly, soil moisture sensor-based smart controllers use water content data from the sensor to adjust irrigation cycles (Dukes, 2009; Dukes et al., 2008). By monitoring site-specific conditions and controlling irrigation systems based on plant water requirements, ET and SMS controllers reduce excess water use due to over-irrigation (Davis and Dukes, 2012; IA and ASIC, 2014; Mutchek and Williams, 2010; St. Hilaire et al., 2008).

The IA has developed testing protocols for assessing the performance of ET and SMS controllers and the U.S. Environmental Protection Agency (EPA) has based its WaterSense product labeling criteria on these protocols (Dukes, 2012; IA, 2013). Parameters that are tested include irrigation adequacy (measure of under-irrigation) and scheduling efficiency (measure of over-irrigation) (Dukes, 2012; IA, 2013).

Plot-based studies of ET and SMS controllers performed in Florida have indicated significant water savings and good turf quality levels 
relative to traditional time-based irrigation schedules. ET controllers tested in central and southwest Florida averaged $25 \%$ to $63 \%$ seasonal water savings and $43 \%$ annual water savings, respectively, compared with University of Florida Institute of Food and Agricultural Sciences (UF/IFAS)recommended time-based treatments that replaced $100 \%$ of the net irrigation requirement without using a rain sensor (Davis et al., 2009; McCready et al., 2009). Moreover, ET controllers were about twice as effective as a rain sensor alone in reducing irrigation in the southwest Florida study (Davis and Dukes, 2012). In Citra and Gainesville, SMS controllers tested during normal to wet weather conditions on average reduced the amount of irrigation scheduled to be applied by $42 \%$ and $72 \%$, respectively, compared with a treatment without a rain sensor with a 2-d-per-week irrigation frequency, included to simulate homeowner irrigation systems (Cárdenas-Lailhacar et al., 2008; McCready et al., 2009). Water savings during dry weather conditions averaged $27 \%$ and $54 \%$, respectively (Cárdenas-Lailhacar et al., 2008; McCready et al., 2009).

Pilot-based studies have shown somewhat less consistent water savings. A cooperator study that tested one brand of SMS in a southwest Florida residential setting found it resulted in $65 \%$ less water used when compared with homes with only timers (Haley and Dukes, 2012) while another cooperator study testing an ET brand under residential conditions in southwest Florida indicated substantial water savings could only be achieved if household irrigation was more than the gross irrigation requirement (Davis and Dukes, 2012).

Pilot-based studies reveal the impacts that real-world conditions have on the effectiveness of smart controllers. Lack of education for contractors and end-users contributes to the divergence between potential savings in plot-based studies and realized savings in pilot projects (Dukes, 2012). Research suggests the setup of smart controllers requires someone with technical knowledge in horticulture and landscape irrigation management (Mayer and DeOreo, 2010; McCready et al., 2009; Pittenger et al., 2004; St. Hilaire et al., 2008). McCready et al. (2009) note "proper installation (e.g., correct location and set point selection for sensor) and programming are essential to balancing water conservation and acceptable turf quality." In their study, they found that one ET-based treatment produced less than acceptable turf quality due to an inappropriate default setting. They also found that SMS-based treatments resulted in low turf quality when set at low thresholds and little water savings when set at high thresholds while medium threshold settings produced good turf quality levels and water savings between $20 \%$ and $51 \%$ (McCready et al., 2009). The programmed frequency of irrigation schedules also affects whether scheduled events are bypassed (i.e., affects SMS precision) (Cárdenas-Lailhacar and Dukes, 2012). Thus, implementation techniques are essential to maximizing the water savings of smart controllers.

Homeowner attitudes and behaviors can also impact the irrigation optimization of smart controllers. Hurd et al. (2006) note that homeowner management of irrigation technology and landscape components contribute to system efficiency. Their survey research found household attitudes toward water resources and conservation overlapped with landscape choices. In another survey study, Wolters (2014) found that water-conserving landscaping and irrigation behaviors were predicted by environmental attitudes scored through the New Ecological Paradigm Scale (Dunlap et al., 2000) as well as by age, gender, and income. Bremer et al. (2012) suggest that homeowner irrigation practices are moderated by lawn-irrigation perceptions and knowledge as well as concerns about water bills.

Given the implications of homeowner demographics, perceptions, technical knowledge, and management of the landscape and irrigation system to the effectiveness of water-saving irrigation devices, the lack of literature on homeowner response to smart controllers is problematic. Until now, the bulk of the literature on smart irrigation for urban landscapes has focused on performance dimensions. However, if water purveyors are to successfully promote smart controllers in an effort to reduce public-supply water demand and conserve groundwater, feedback from end-users is critical.

This paper provides an evaluation of homeowner response to ET and SMS controllers installed as part of a smart irrigation pilot project conducted in Orange County, FL from May 2011 to June 2013. The purpose of the evaluation, designed and performed by a team of agricultural education and communication faculty and research staff, was to gauge reception to smart irrigation technology. The study's objectives were to collect demographic information, assess conservation attitudes and irrigation system knowledge, and gather feedback on the use of smart controllers from the pilot project's residential cooperators.

\section{Materials and Methods}

BACKGround. The Orange County smart irrigation pilot project was developed to address growing public water demands in central Florida (Dukes, 2008). As part of its objective to test the potential level of water conservation of smart irrigation devices in diverse areas of Orange County covering different soil types under residential conditions, the project enlisted the cooperation of 167 homeowners across a single Orange County water utilities service area (Dukes, 2008). The selection of project cooperators was guided by the following criteria: the homeowner's length of residence at the property exceeded 2 years, the residence had an in-ground irrigation system that used potable water and included an automatic time-clock or controller, and the homeowner's estimated irrigation exceeded the average monthly theoretical limit by 1.5 to 4 times and at least 3 months out of every year between 2006 and 2008 (Romero et al., 2011). The estimated irrigation and theoretical irrigation requirements for each potential home were calculated using water-use data provided by the collaborating water utilities company, GIS aerial image data, and evapotranspiration data available from public sources (Dukes, 2008; Romero et al., 2011). Selected residences had one of the following treatments installed at no charge: contractor-programmed ET controller (ET), contractor-programmed soil moisture sensor (SMS), universityprogrammed ET controller with brief, on-site educational tutorial lasting $\approx 5 \mathrm{~min}(\mathrm{ET}+\mathrm{Edu})$, universityprogrammed soil moisture sensor with brief, on-site educational tutorial 
lasting $\approx 5 \min (\mathrm{SMS}+\mathrm{Edu})$, or monitoring only (MO) for comparison (Davis, 2014). Devices installed as part of the pilot project became the homeowners' responsibility after the research was completed (Romero et al., 2011). Data reported here were obtained from 16 Jan. to 21 Mar. 2014 through a posttest survey of the project's residential cooperators.

Survey instrument. A posttest survey questionnaire, organized into several blocks of items, was developed to investigate factors affecting shortterm and long-term adoption of smart irrigation controllers. The first block of items consisted of baseline questions regarding the landscape and irrigation system. The second block of items elicited feedback regarding the performance of the installed controllers as well as positive and negative features of smart irrigation technology. The next block contained knowledge test questions regarding the installation and functioning of smart controllers. The last block of items requested demographic information from participant households.

To tailor the questionnaire to each of the treatments, it was modified into five separate instruments. The language and item blocks of each instrument corresponded to the technology and information received by each treatment group. For example, ET and $\mathrm{ET}+\mathrm{Edu}$ questionnaires only elicited information specific to ET controllers while SMS and SMS+Edu questionnaires only elicited information specific to SMS controllers. Because cooperators in the MO treatment did not have smart irrigation technology installed on their properties, the MO questionnaire only contained baseline, technical knowledge, and demographic question blocks. ET+Edu and SMS+Edu questionnaires contained the complete set of item blocks whereas ET and SMS questionnaires omitted items relevant only to the Edu treatments.

The five instruments were prepared for online distribution using survey software (Qualtrics Research Suite version 2013; Qualtrics, Provo, UT). Copies of the final instruments were reviewed by university faculty in the departments of Agricultural Education and Communication, Food and Resource Economics, and Agricultural and Biological Engineering and by staff of the collaborating water utilities company. As an evaluation component of the Orange County smart irrigation pilot project, the survey research was exempted by the university's Social and Behavioral Institutional Review Board.

Data collection. The posttest survey was conducted using procedures adapted from the Tailored Design Method (Dillman, 2007). Prenotice letters, crafted to alert recipients that they would soon be invited to participate in an important survey, were mailed on 14 Jan. 2014 from the water utilities company to the project's 167 residential cooperators. Personalized invitations explaining the purpose of the survey and containing a link to the appropriate online questionnaire were e-mailed 2 d later through Qualtrics. Cooperators without e-mail addresses and cooperators who notified the utilities company or the university research team that they preferred a mail survey were mailed packages containing a personalized cover letter invitation, the appropriate paper questionnaire, and a stamped envelope addressed to the university Department of Agricultural Education and Communication.

Upon completing the survey, online respondents received thank you e-mails automatically sent through Qualtrics. Mail respondents received thank you postcards within 1 week of returning their paper questionnaires.

A little over 1 week after e-mailing survey invitations, online nonrespondents were sent personalized e-mail reminders through Qualtrics. Mail nonrespondents were sent personalized postcard reminders. E-mail and street addresses were updated for cooperators whose correspondence was returned.

Fifteen days following the first reminder, a second, more urgent, reminder was sent to online nonrespondents through Qualtrics. Mail nonrespondents were sent replacement questionnaires accompanied by personalized letter reminders and stamped, addressed envelopes.

About 5 weeks after the initial survey invitation, remaining online nonrespondents were sent a final reminder by both mail and e-mail informing them the survey was soon coming to a close. Remaining mail nonrespondents were likewise sent a final letter reminder.

Data Analysis. Relative frequency distributions were used to capture trends in responses to multiplechoice and Likert-type items. Responses were disaggregated by treatment unless the item contained multiple questions or provided the option of selecting all applicable choices. In those cases, responses were aggregated or they were disaggregated by technology to compare the experiences of cooperators with ET and SMS installations.

Text responses to open-ended questions were coded according to one to four keywords appearing in or summarizing each response. For example, a text response to the openended question, "can you provide an example of a challenge you experienced with your SMS?" answering, "the sensor was located in too dry a spot resulting in overwatering" was coded "sensor location" and "overwatering." A set of keywords was compiled for each set of item responses. Frequency counts were then calculated for each keyword and graphed in pie charts for each item.

Responses to four closed-ended technical knowledge test questions regarding the installation and functioning of the relevant controller were graded for accuracy (as were six technical knowledge test questions in the MO questionnaire regarding both ET and SMS controllers). A percentage of correct responses was generated for each respondent. Relative frequency distributions were used to compare average test scores between treatments.

Independent means $t$ tests in SPSS (version 22.0; IBM, Armonk, $\mathrm{NY}$ ) were used to assess whether the average number of survey respondents with ET and SMS controllers who experienced challenges and dissatisfaction were statistically different from each other. Independent means $t$ tests were also used to compare average technical knowledge test scores between survey respondents with ET and SMS controllers.

Logistic regression analysis in SPSS was used to identify factors associated with the likelihood of continuing to use ET and SMS controllers after the completion of the project. This was done to judge whether project or non-project variables contributed to differences in responses in dependable ways. This type of analysis was feasible because the dependent variable was a categorical variable coded as 1 or 0 while the 
independent variables were either continuous quantitative variables or categorical variables coded as 1 or 0 . The independent variables selected to estimate the likelihood of continuing to use the installed controllers included satisfaction with current irrigation practices, satisfaction with the appearance of the lawn/landscape, belief in the installed controller's water-saving effectiveness, receipt of a brief tutorial, technical knowledge test score, experience of any challenges with the controller, and age. Variance inflation factors (VIF) and Pearson correlation were used as diagnostic tools to detect the presence of multicollinearity among the predictor variables. However, VIF values did not exceed 1.34 and variables did not correlate highly $(R<0.38)$, suggesting multicollinearity was not an issue.

\section{Results}

SURVEY RESPONSE AND COMPLETION RATES. Of the 167 residential cooperators invited to take the Orange County smart irrigation pilot project's posttest survey, 125 took the online survey and 18 took the mail survey, resulting in an $86 \%$ overall survey response rate. Of the 125 respondents who took the online survey, 120 finished it. The other five did not complete more than four items and were removed from the dataset. All 18 mail survey respondents finished the paper questionnaires. Thus, the final dataset included responses from 138 survey participants. The number of survey participants from each treatment group was as follows: $\mathrm{MO}=23$, $\mathrm{SMS}=22, \mathrm{ET}=26, \mathrm{SMS}+\mathrm{Edu}=$ $29, \mathrm{ET}+\mathrm{Edu}=38$. The percentage of survey participants in each treatment was roughly the same as the percentage of project cooperators in each treatment.

Demographics. Survey items requesting demographic information centered on highest level of schooling completed, household income, age, and gender. Responses indicated survey participants were largely college graduates or professionals with household incomes starting at $\$ 75,000$. Eighty-six percent of survey participants reported the completion of at least 2 years of college or vocational training. Sixty-nine percent reported household incomes of $\$ 75,000$ or more. On average, survey participants who responded to the item regarding age were between 50 and 58 years old $(\mathrm{MO}$ : mean $=50.39$, $\mathrm{SD}=7.82 ;$ SMS: mean $=57.82, \mathrm{SD}=$ $8.52 ;$ ET: mean $=54.64, \mathrm{SD}=9.02$; SMS+Edu: mean $=53.11, S D=$ 9.02; ET+Edu: mean $=56.47, \mathrm{SD}=$ 12.32). The sex ratio of survey participation was roughly two males to one female, overall.

WATER-USE AND CONSERVATION ATTITUDES AND BEHAVIORS. Survey participants' attitudes and behaviors regarding water use and conservation were explored through a Likert-type question that included 10 statements about irrigation and outdoor water usage and asked respondents to rate their level of agreement with each. Aggregated survey responses, summarized in Fig. 1, show that the majority of survey participants felt outdoor water conservation saved money (95\%), felt knowledgeable about water restrictions $(89 \%)$, believed a rain shut-off device was important $(85 \%)$, and believed their own conservation of water affected the overall water supply $(80 \%)$. At the same time, the majority also were aware of lawn appearance requirements within their neighborhood $(88 \%)$ and were very concerned about the appearance of their yard $(85 \%)$. Thirty-three percent agreed they spent a lot of time on their lawn/ landscape while 36\% disagreed. Fifty percent had often observed their neighbors over-irrigating. While $41 \%$ of survey participants said they did not irrigate more because of environmental concern, $51 \%$ felt they tended to water their lawn more when it did not rain regularly.

Baseline Data. Closed-ended baseline items elicited levels of satisfaction with irrigation practices and landscape appearance as well as information regarding the service and maintenance of the sprinkler system from all survey participants. Responses

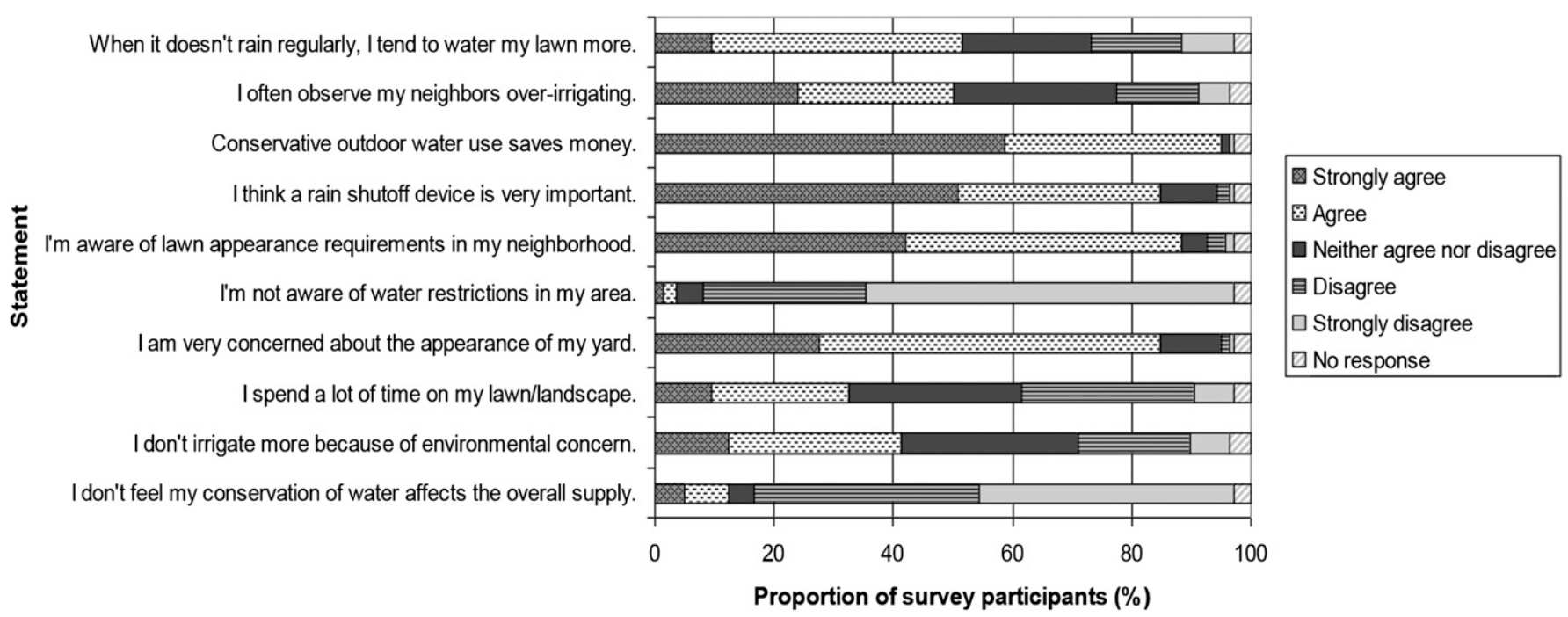

Fig. 1. Relative frequency distribution of aggregated responses $(n=138)$ to the multiple-choice question, "please indicate your agreement with the following statements about irrigation and outdoor water usage" from survey participants in all treatment groups. Treatment groups received one of the following: contractor-programmed soil moisture sensor (SMS), contractorprogrammed ET controller (ET), university-programmed soil moisture sensor with on-site educational tutorial (SMS + Edu), university-programmed ET controller with on-site educational tutorial (ET + Edu), or monitoring only (MO). 
regarding satisfaction with current irrigation practices are illustrated in Fig. 2A. The graph indicates most survey participants reported they were satisfied or very satisfied with their current irrigation practices. Eightyseven percent of survey participants in the ET+Edu treatment selected one of these two responses, the highest level of satisfaction among the five treatments. On the other hand, $61 \%$ of survey participants in the MO treatment reported being satisfied or very satisfied with their irrigation practices, the lowest level of satisfaction among the five treatments. Fourteen percent, $14 \%$, and $9 \%$ of survey participants in the SMS+Edu, SMS, and MO treatments, respectively, reported dissatisfaction with their irrigation practices. Four percent of survey participants in the ET treatment reported being very dissatisfied with their irrigation practices. Seven percent of survey participants in the SMS+Edu treatment did not respond to the item.

Figure $2 \mathrm{~B}$ illustrates survey responses regarding satisfaction with the current appearance of the lawn/ landscape. In comparison with the previous graph, this graph shows a wider range of responses. Survey participants in the ET treatment, 77\% of whom reported they were either satisfied or very satisfied with the appearance of their lawn/landscape, expressed the greatest level of satisfaction. Survey participants in the MO treatment again expressed the greatest level of dissatisfaction, $26 \%$ of whom reported they were either dissatisfied or very dissatisfied with the appearance of their lawn/landscape. Seventeen percent of SMS+Edu, $14 \%$ of SMS, $13 \%$ of ET+Edu, and $8 \%$ of ET survey
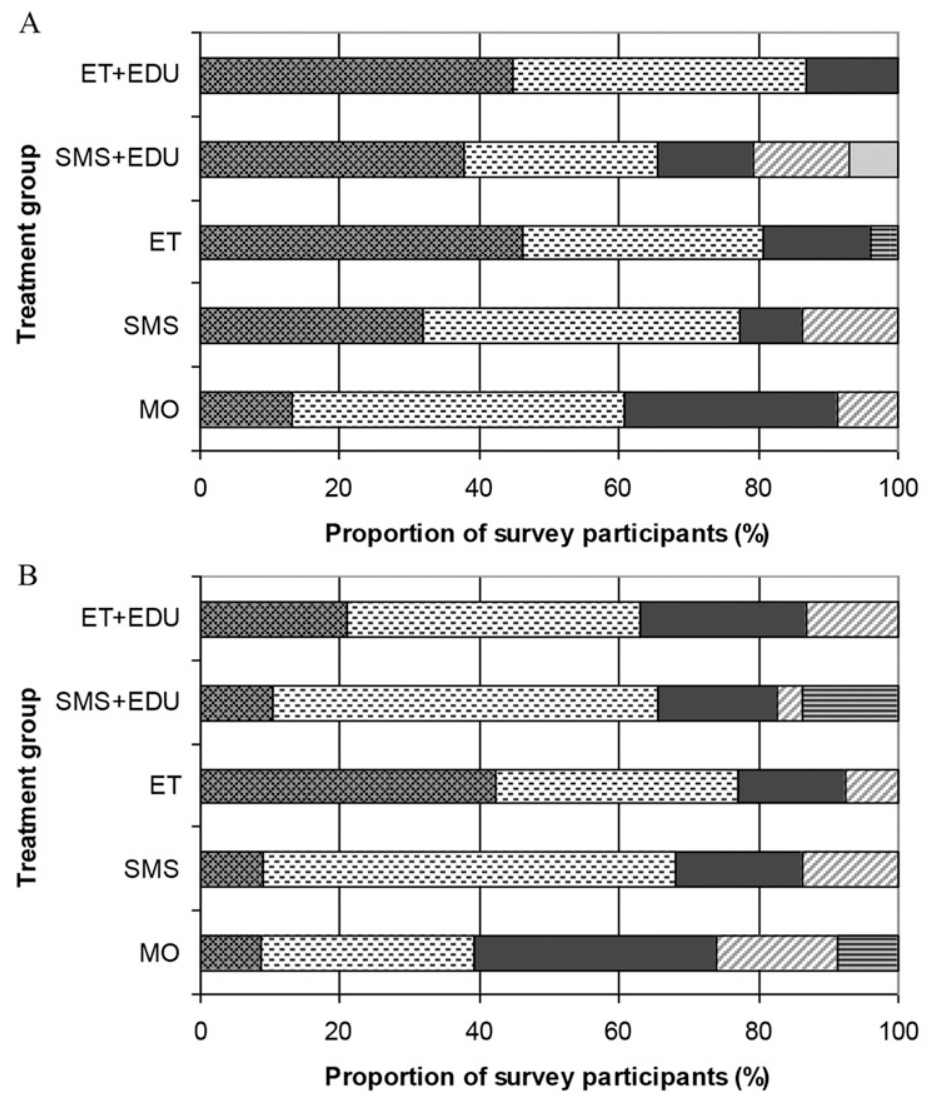

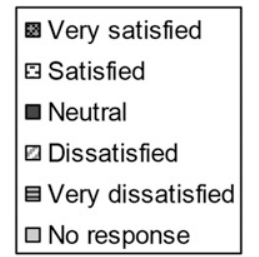

Fig. 2. Relative frequency distributions of responses to the multiple-choice questions "how satisfied are you with your current irrigation practices?" (A) and "how satisfied are you with the current appearance of your lawn/landscape?" (B) from survey participants in each of the treatment groups. Treatment groups received one of the following: contractor-programmed soil moisture sensor (SMS), contractor-programmed ET controller (ET), university-programmed soil moisture sensor with on-site educational tutorial (SMS + Edu), university-programmed ET controller with on-site educational tutorial (ET + Edu), or monitoring only (MO). Responses were disaggregated by treatment: SMS $(n=22)$, ET $(n=26)$, SMS + Edu $(\mathrm{n}=29), \mathrm{ET}+\operatorname{Edu}(\mathrm{n}=38)$, MO $(\mathrm{n}=23)$. participants selected one of those two responses.

Aggregated survey responses in reply to the baseline multiple-select item, "Who services and/or repairs your sprinkler system?" indicated $57 \%$ of survey participants serviced or repaired their sprinkler systems on their own at least part of the time. An irrigation specialist did so for $38 \%$ of participants while a landscaper for $19 \%$ of participants. Four percent of survey participants reported someone other than themselves, an irrigation specialist, or a landscaper serviced and/or repaired the sprinkler system while $3 \%$ reported that no one (even themselves) did so. One percent of survey participants provided no response.

SMART CONTROLLER USER Feedback: Closed-ended items. Questions in the survey's second block of items, viewed only by respondents in the SMS, ET, SMS+Edu, and ET+Edu treatments, elicited feedback regarding installed smart irrigation controllers. The first item in the block asked, "How satisfied are you with the smart controller that was installed on your property?" Responses were disaggregated by treatment and are summarized in Fig. 3. The graph indicates $81 \%$ of survey participants in the ET treatment and $81 \%$ in the ET+Edu treatment reported they were either satisfied or very satisfied with their smart irrigation technology. Sixtyeight percent of survey participants in the SMS treatment and $65 \%$ in the SMS+Edu treatment reported likewise. On the other hand, $14 \%$ of survey participants in the SMS+Edu treatment reported they were very dissatisfied with their controllers and another $10 \%$ reported they were dissatisfied. Eighteen percent of survey participants in the SMS treatment and $5 \%$ in the ET+Edu treatment reported they were dissatisfied with their smart irrigation technology.

While Fig. 3 illustrates that, overall, most survey participants were either satisfied or very satisfied with the smart controllers that were installed on their properties, it also shows a pocket of dissatisfaction among participants with SMS controllers (in SMS and SMS+Edu treatments). An independent means $t$ test was performed to confirm whether these levels of dissatisfaction were statistically different from levels of 


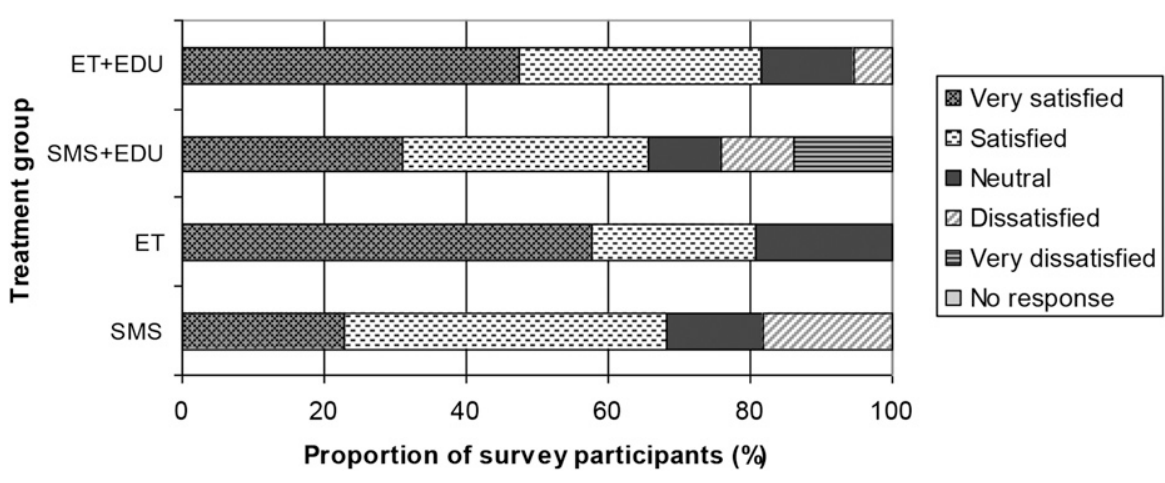

Fig. 3. Relative frequency distribution of responses to the multiple-choice question, "how satisfied are you with the smart controller that was installed on your property?" from survey participants in each of the controller treatment groups. Controller treatment groups received one of the following: contractor-programmed soil moisture sensor (SMS), contractor-programmed ET controller (ET), university-programmed soil moisture sensor with on-site educational tutorial (SMS + Edu), or university-programmed ET controller with on-site educational tutorial $(\mathrm{ET}+\mathrm{Edu})$. Responses were disaggregated by treatment: SMS $(\mathbf{n}=22)$, $\mathrm{ET}(\mathrm{n}=26), \mathrm{SMS}+\mathrm{Edu}(\mathrm{n}=29), \mathrm{ET}+\operatorname{Edu}(\mathrm{n}=38)$.

dissatisfaction among participants with ET controllers (in ET and $\mathrm{ET}+\mathrm{Edu}$ treatments). Results indicate that, on average, a greater number of survey participants with SMS technology $($ mean $=0.22, \mathrm{SE}=$ 0.06 ) reported they were either dissatisfied or very dissatisfied with their controllers than did survey participants with ET technology $($ mean $=0.03, \mathrm{SE}=0.02)$. This difference was significant $[t(\mathrm{df}=$ 64) $=2.97, P=0.004 ; r=0.35]$.

The second item in the userfeedback question block explored survey participants' potential longterm adoption of smart irrigation technology by asking, "How likely are you to continue using your smart controller after the completion of the Orange County smart irrigation pilot project?" Responses were disaggregated by treatment and indicated, overall, that most survey participants would likely continue using their controllers. One hundred percent of survey participants in the ET treatment and $95 \%$ in the ET+Edu treatment reported they would either likely or very likely continue using them. Eighty-three percent of survey participants in the SMS+Edu treatment and $73 \%$ in the SMS treatment reported likewise. Nonetheless, 10\% of survey participants in the SMS+Edu treatment and $5 \%$ in the SMS treatment reported it was either unlikely or very unlikely that they would continue using their controllers after the completion of the project. Another $5 \%$ of survey participants in the SMS treatment did not provide a response.

Another item asked, "How comfortable do you feel operating your smart controller?" Responses indicated that the highest levels of comfort were experienced by survey participants in the ET and SMS treatments. Seventy-seven percent of survey participants in the ET treatment and 69\% in the SMS treatment reported they felt either comfortable or very comfortable operating their controllers. In contrast, $55 \%$ of survey participants in the ET+Edu treatment and $55 \%$ in the SMS+Edu treatment reported likewise. Twenty-four percent of survey participants in the ET+Edu treatment and $17 \%$ in the SMS+Edu treatment reported they felt either uncomfortable or very uncomfortable operating their controllers.

The last of the closed-ended userfeedback items was a "yes or no" question that asked, "Have you experienced any challenges with your smart controller?" Responses indicated that, overall, most survey participants had not experienced any challenges with their installed controllers. Eighty-five percent of survey participants in the ET treatment, $74 \%$ in the ET+Edu treatment, $64 \%$ in the SMS treatment, and 59\% in the SMS+Edu treatment selected "no" in response to the question. However, $41 \%$ in the SMS+Edu treatment and $36 \%$ in the SMS treatment reported they had experienced challenges. Twenty-six percent of survey participants in the $\mathrm{ET}+\mathrm{Edu}$ treatment and $15 \%$ in the ET treatment reported likewise.
Because responses revealed that a greater percentage of survey participants in the SMS and SMS+Edu treatments than in the ET and $\mathrm{ET}+\mathrm{Edu}$ treatments had experienced challenges, an independent means $t$ test was performed to confirm whether there was a statistical difference between these two percentages. Results indicate that, on average, a significantly $[t(\mathrm{df}=98)=2.01, P=$ $0.048 ; r=0.20]$ greater number of survey participants with SMS installations $($ mean $=0.39, \mathrm{SE}=0.07)$ experienced challenges with their controllers than did survey participants with ET installations (mean = $0.22, \mathrm{SE}=0.05)$.

SMART CONTROLLER USER FEEDBACK: OPEN-ENDED ITEMS. Several survey items sought greater feedback regarding residential cooperators' experiences with their smart irrigation controllers than could be elicited through a fixedchoice format and thus provided text boxes for more in-depth responses. These items asked respondents (in SMS, ET, SMS+Edu, and ET+Edu treatments) to provide examples of challenges they experienced with their controllers and the ways in which the challenges were addressed. Respondents were also asked to describe the best part of using the technology.

The particular challenges respondents experienced with their smart controllers are summarized in Fig. 4A and B. Only those survey participants who had earlier selected "yes" in response to the item, "Have you experienced any challenges with your smart controller?" were asked to provide examples. To the right of each pie graph are the keywords that appeared in or summarized their text responses. The pie graphs represent relative frequency counts of the keywords compiled for each item.

Figure $4 \mathrm{~A}$ shows timing (bypass) issues were the challenge most frequently encountered by respondents with SMS controllers. For example, one respondent wrote that her SMS "runs two times in a row" and she must "shut it off manually" while another respondent said his SMS "waits too long to water and then waters two days in a row." The second most frequently cited challenge among respondents with SMS controllers was the location of the sensor. 


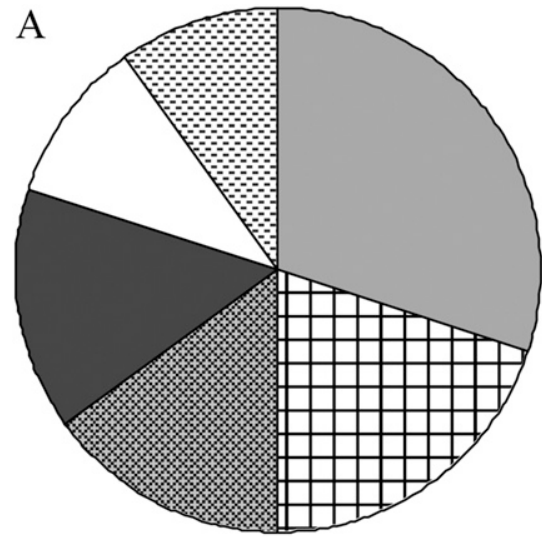

\begin{tabular}{l}
\hline Timing (bypass) issues \\
$\boxplus$ Sensor location \\
⿴囗大 Lack of instruction \\
$\square$ Adjustment/recalibration \\
$\square$ Single sensor for all zones \\
웅 Insufficient watering
\end{tabular}

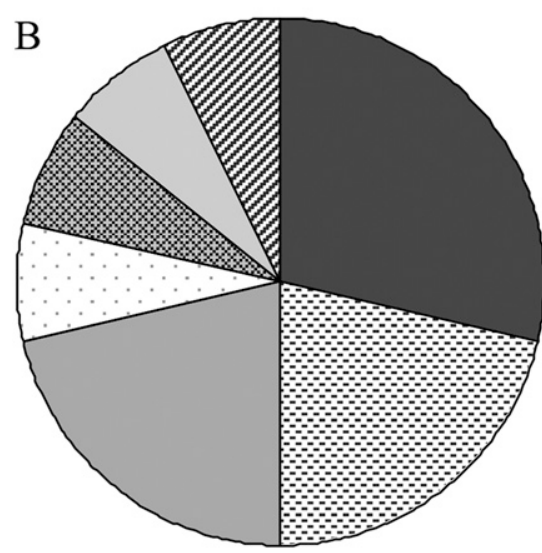

$\square$ Settings adjustment
$\square$ Insufficient watering
$\square$ Timing of irrigation events
$\square$ Overwatering
Lack of instruction
$\square$ Poor installation
$\square$ Noise

Fig. 4. Relative frequency counts of keywords describing the types of challenges experienced with soil moisture sensor (SMS) (A) and evapotranspiration (ET) controllers (B). Keywords were identified from survey participants' open-ended text responses to the question, "can you provide an example of a challenge you experienced with your smart controller?" The question was viewed only by survey participants in controller treatment groups who had earlier answered "yes" to the question, "have you experienced any challenges with your controller?" Controller treatment groups received one of the following: contractor-programmed soil moisture sensor (SMS), contractor-programmed ET controller (ET), universityprogrammed soil moisture sensor with on-site educational tutorial (SMS + Edu), or university-programmed ET controller with on-site educational tutorial (ET + Edu). Responses were disaggregated by technology: SMS and SMS + Edu $(n=20)$, ET and $\mathrm{ET}+\mathrm{Edu}(\mathrm{n}=14)$.

One respondent stated, "I don't feel the sensor was located in the proper location because parts of my yard dried out." Another wrote, "The moisture sensor is located in a lower section of my lawn where it is fairly moist [which] tends to affect other areas by leaving them too dry at times.”

Figure 4B shows respondents with ET controllers most frequently cited challenges in adjusting their settings. For instance, one respondent's settings "somehow got deactivated and it was very hard to put the original setting in" while another responded, "figuring out how to reset ... has not been very intuitive for me." The next most frequently encountered challenge among respondents with
ET controllers was insufficient watering. One respondent noted "the front yard did not receive adequate water at first-had to adjust for an increase [and] still could use more water to the front than it gets." Another wrote that his ET "does not provide enough water to lawn under trees."

Responses regarding ways in which challenges with smart controllers were addressed indicated that across both sets of treatments (SMS and SMS+Edu: $\mathrm{n}=20 ; \mathrm{ET}$ and ET+Edu: $\mathrm{n}=14$ ), respondents most frequently called a professional when they encountered a challenge. Professionals included staff from the university, manufacturers, Orange County, and irrigation companies. For example, a respondent with an SMS controller "called the university support number" while another with an ET controller was "directed to call Orange County Water Department." The second most frequently cited way in which respondents in both treatments addressed challenges with their controllers was manual override. A respondent wrote about his SMS controller: "I manually overrode the system to water before the system would allow watering." Similarly, a respondent with an ET controller noted he "overrode manually to force watering."

All survey participants in SMS, ET, SMS+Edu, and ET+Edu treatments were asked to describe the best part of using their smart irrigation technology. Figure $5 \mathrm{~A}$ and $\mathrm{B}$ show saving money and efficient irrigation were the two most frequently cited best features of both technologies, sometimes described together. One respondent wrote that his SMS "saves on the water bill and reduces overwatering the landscape." Another respondent noted his ET "saves money as a result of a more efficient use of irrigation." Yet these features were also cited individually. One respondent simply said the best part of using an SMS was "saving money." Another respondent with an ET elaborated: "When it's been raining it's reassuring to see that the system automatically suspended irrigation."

Technical KnOwledge. The knowledge test question portion of the survey was designed to gauge residential cooperators' familiarity with their installed controllers. Survey participants in the SMS, ET, SMS+Edu, and ET+Edu treatments were first asked whether they understood how their controllers worked and subsequently presented with four technical knowledge test questions regarding the installation and functioning of the assigned controllers. Survey participants in the MO treatment were instead simply presented with six technical knowledge test questions regarding both SMS and ET controllers.

Self-reported knowledge levels indicated most survey participants felt they understood how their controllers worked. Eighty-three percent in the SMS+Edu treatment, $82 \%$ in the SMS treatment, $73 \%$ in the ET treatment, and $68 \%$ in the ET+Edu treatment reported they understood how 

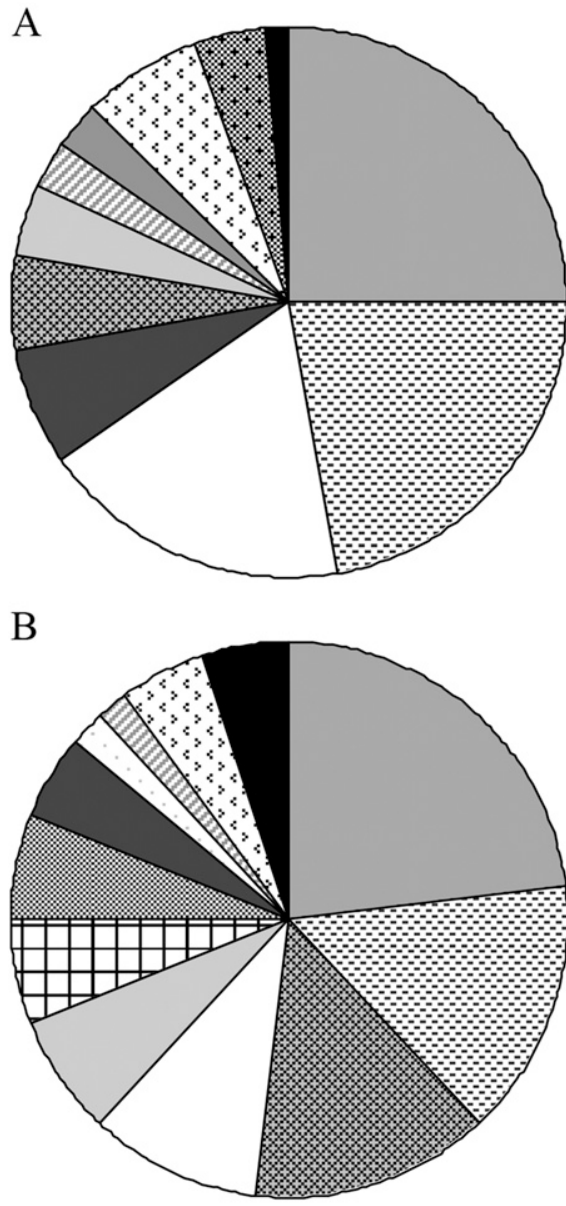

\begin{tabular}{|l|}
\hline$\square$ Saving money \\
⿴囗玉 Efficient irrigation \\
$\square$ Saving/conserving water \\
$\square$ Technological feature(s) \\
Nice lawn/landscape \\
$\square$ Set and forget \\
$\square$ Knowledge \\
$\square$ University collaboration \\
$\square$ Other \\
$\square$ Not applicable \\
No response \\
\hline
\end{tabular}

\begin{tabular}{|l|}
\hline Saving money \\
⿴囗 Efficient irrigation \\
⿴ Nice lawn/landscape \\
$\square$ Saving/conserving water \\
$\square$ Set and forget \\
$\square$ Ease \\
Restriction exemption \\
$\square$ Technological feature(s) \\
$\square$ Using new technology \\
$\square$ Knowledge \\
$\square$ Other \\
$\square$ No response \\
\hline
\end{tabular}

Fig. 5. Relative frequency counts of keywords describing the best part of using soil moisture sensor (SMS) (A) and evapotranspiration (ET) controllers (B). Keywords were identified from open-ended text responses to the question, "what do you feel has been the best part of using this irrigation technology?" provided by survey participants in controller treatment groups. Controller treatment groups received one of the following: contractor-programmed soil moisture sensor (SMS), contractorprogrammed ET controller (ET), university-programmed soil moisture sensor with on-site educational tutorial (SMS + Edu), or university-programmed ET controller with on-site educational tutorial $(\mathrm{ET}+\mathrm{Edu})$. Responses were disaggregated by technology: SMS and SMS + Edu $(n=51)$, ET and ET + Edu $(n=64)$.

their controllers worked. Nonetheless, almost a third of ET+Edu and almost a quarter of ET survey participants reported they did not understand how their controllers worked. Seventeen percent in the SMS+Edu treatment and $18 \%$ in the SMS treatment reported likewise.

Subsequent responses to technical knowledge test questions were graded and a score was generated for each survey participant. There was only one correct response to each multiple-choice item and responses were graded as either correct or incorrect. Non-responses and "I do not know" choice selections were graded as incorrect. Scores were generated as a ratio of correct to incorrect responses and averaged for each treatment. Survey participants in the ET treatment, on average, answered correctly to $42 \%$ of the test items. Similarly, in the ET+Edu treatment the average score was $41 \%$. Survey participants in the SMS and SMS+Edu treatments had somewhat lower scores. In the SMS treatment the average was $33 \%$ and in the SMS+Edu treatment it was $23 \%$. Survey participants in the MO treatment, on average, answered correctly to $12 \%$ of their test items.

While most survey participants scored poorly on the technical knowledge test items, a limitation of gauging knowledge in just a few questions, results indicate participants with ET controllers had higher scores than did participants with SMS controllers. An independent means $t$ test was performed to confirm whether the two sets of test scores were statistically different. Results indicate that, on average, survey participants with ET controllers had significantly $[t(\mathrm{df}=$ $111)=-3.24, P=0.002 ; r=0.29]$ higher technical knowledge test scores $($ mean $=0.41, \mathrm{SE}=0.03)$ than did survey participants with SMS controllers $($ mean $=0.27, \mathrm{SE}=0.03$ ).

To explore the role of technical knowledge as well as other project and non-project variables in the potential long-term adoption of smart irrigation controllers, logistic regression analysis was conducted to predict the likelihood of continuing to use the installed controller after the project's completion. All variables included in the regression model, except age and technical knowledge test score, were categorical (yes $=1$, no $=0)$. A sample size of $n=107$, the number of survey participants who did not omit responses to regression model variables, was used for the analysis. Table 1 lists the predictors and illustrates results. It shows that test score $(P=0.030)$ and the experience of challenges with the controller $(P=0.006)$ were the only statistically significant predictors of whether survey participants would likely continue using them. According to the regression model, the odds of likely continuing to use an installed controller were four times higher per one point increase (one more correct item response) in the technical knowledge test score. A test of the full model against a constant-only model was statistically significant $\left(\chi^{2}=30.78, P=0.000\right)$ indicating the set of predictors reliably distinguished between likely and not likely continuing to use the controller.

\section{Discussion}

Results of the posttest survey conducted for the Orange County smart irrigation pilot project point to four main findings. First, a majority of survey participants with smart irrigation technology were generally satisfied with their controllers and planned to continue using them. A second finding is that a significantly greater number of survey participants with SMS controllers experienced challenges, dissatisfaction, and scored 
Table 1. Results of logistic regression analysis performed to evaluate the effects of homeowners' perceptions, experiences, knowledge, and age on the likelihood of continuing to use their installed controllers after the completion of the Orange County, FL smart irrigation pilot project, based on $(n=107)$ valid responses to survey questions regarding the regression model's dependent and independent variables.

\begin{tabular}{|c|c|c|c|c|}
\hline Predictor $^{\mathrm{z}}$ & Coefficient & SE & Wald $\chi^{2 y}$ & Odds ratio \\
\hline (Constant) & -3.41 & 2.72 & 1.57 & 0.03 \\
\hline Satisfied with irrigation practices & 1.30 & 0.85 & 2.37 & 3.68 \\
\hline Satisfied with the appearance of lawn/landscape & 0.67 & 0.82 & 0.68 & 1.96 \\
\hline Considers controller effective in saving water & 0.69 & 0.79 & 0.76 & 1.99 \\
\hline Feels own conservation of water affects overall supply & 1.03 & 1.08 & 0.91 & 2.79 \\
\hline Received tutorial & 1.04 & 0.85 & 1.50 & 2.84 \\
\hline Age & 0.04 & 0.04 & 0.85 & 1.04 \\
\hline
\end{tabular}

${ }^{z}$ The logistic model explained $48 \%$ of the variation in the dependent variable, indicated by $R^{2}=0.48$ (Nagelkerke, 1991 ).

y The Wald criterion demonstrated that the only significant predictors were technical knowledge test score $\left({ }^{*} P=0.030\right)$ and whether any challenges were experienced with the controller $\left({ }^{*} P=0.006\right)$.

lower on tests designed to gauge familiarity with the workings of their devices than did survey participants with ET controllers. A third finding is that the 5-min tutorial provided to survey participants in the SMS+Edu and ET+Edu treatments did not seem to be sufficient to increase their knowledge of the devices nor their levels of comfort operating them beyond that of survey participants in other controller treatments, likely because it was too brief. A fourth finding is that, consistently, survey participants praised both SMS and ET controllers for saving them money and irrigating efficiently.

In addition, survey participants with smart irrigation technology were not just generally satisfied with their controllers. They were also generally pleased with their irrigation practices and the appearance of their lawn/ landscape-more so than participants without smart controllers. Yet, results suggest that respondents valued other benefits (e.g., saving money and irrigating efficiently) above having a nice lawn/landscape. This finding is in line with the conclusion of Bremer et al. (2012), that homeowner irrigation practices are moderated by lawnirrigation perceptions and concerns about water bills.

Results of logistic regression analysis confirm these findings for the most part. According to the regression model, neither satisfaction with irrigation practices nor satisfaction with the appearance of the lawn/ landscape was a significant predictor of the likelihood of continuing to use the installed controller after the project's completion. Feeling one's own conservation of water affected the overall water supply was not a significant predictor either, despite Wolters's (2014) results indicating waterconserving irrigation behaviors are associated with environmental attitudes. Instead, technical knowledge test score and whether any challenges were experienced with the controller best predicted the likelihood.

While results imply a greater number of survey participants with SMS installations are likely to discontinue using their controllers after the completion of the project than are survey participants with ET installations, previous studies (Davis and Dukes, 2012, 2014) indicate SMS controllers may realize greater water savings than ET controllers if household irrigation is conservative before installation (i.e., less than the gross irrigation requirement). They are also less expensive. This suggests a potential need to enhance the understanding of SMS controllers, particularly since the gap between self-reported and test knowledge levels was more pronounced among survey participants with SMS controllers and because "lack of instruction" was their third most frequently cited challenge, possibly indicating SMS users could have benefited from a better manual.

Given that $57 \%$ of survey participants serviced or repaired their sprinkler systems on their own at least part of the time, quality guidance and ancillary educational materials are relevant for both SMS and ET users. Previous studies have stressed the importance of implementation techniques to the proper installation and programming of smart controllers and their contribution to water conservation and turf quality
(Cárdenas-Lailhacar and Dukes, 2012; Davis and Dukes, 2010, 2012; Dukes, 2012; Mayer and DeOreo, 2010; McCready et al., 2009; Pittenger et al., 2004; St. Hilaire et al., 2008). Our findings suggest that technical knowledge and successful operation of smart controllers also contribute to homeowners' long-term adoption of the devices.

\section{Conclusion}

Until now, research on smart irrigation controllers for urban landscapes has emphasized performance dimensions. However, if water purveyors are to successfully promote them in an effort to reduce publicsupply water demand and conserve groundwater, evaluating homeowner response to the technology is critical. The results of this study demonstrate the implications of homeowner demographics, water use and conservation attitudes, technical knowledge, and satisfaction in the residential use of SMS and ET controllers. Overall, results indicate that satisfaction with irrigation practices and landscape appearance was higher among the study's homeowners whose properties were installed with SMS and ET controllers. The feature of smart irrigation controllers homeowners liked most was their capacity for saving money. Familiarity with the installation and functioning of the devices increased the likelihood that homeowners would continue using them. Promotion efforts may be most effective by emphasizing the economic benefits of investing in smart irrigation controllers and by disseminating best management practices-both to end-users and contractors-that 
facilitate their understanding and successful operation.

\section{Literature cited}

Bremer, D.J., S.J. Keeley, A. Jager, J.D. Fry, and C. Lavis. 2012. In-ground irrigation systems affect lawn-watering behaviors of residential homeowners. HortTechnology 22:651-658.

Cárdenas-Lailhacar, B. and M.D. Dukes. 2012. Soil moisture sensor landscape irrigation controllers: A review of multistudy results and future implications. Trans. Amer. Soc. Agr. Biol. Eng. 55:581-590.

Cárdenas-Lailhacar, B., M.D. Dukes, and G.L. Miller. 2008. Sensor-based automation of irrigation on bermudagrass, during wet weather conditions. J. Irrig. Drain. Eng. 134:120-128.

Davis, S.L. 2014. Effectiveness of smart controllers for water conservation in residential irrigation. PhD Diss., Univ. Florida, Gainesville.

Davis, S.L. and M.D. Dukes. 2010. Irrigation scheduling performance by evapotranspiration-based controllers. Agr. Water Mgt. 98:19-28.

Davis, S.L. and M.D. Dukes. 2012. Landscape irrigation with evapotranspiration controllers in a humid climate. Trans. Amer. Soc. Agr. Biol. Eng. 55:571-580.

Davis, S.L. and M.D. Dukes. 2014. Irrigation of residential landscapes using the Toro Intelli-Sense controller in southwest Florida. J. Irr. Drain. Eng. 140(3): 04013020-1-04013020-7.

Davis, S.L., M.D. Dukes, and G.L. Miller. 2009. Landscape irrigation by evapotranspiration-based irrigation controllers under dry conditions in southwest Florida. Agr. Water Mgt. 96:1828-1836.

Dillman, D.A. 2007. Mail and internet surveys: The Tailored design method. Wiley, Hoboken, NJ.

Dukes, M.D. 2008. Smart irrigation controller demonstration and evaluation in Orange County, Florida: Project description. Univ. Florida, Gainesville.

Dukes, M.D. 2009. Smart irrigation controllers: What makes an irrigation controller smart? Univ. Florida, Inst. Food Agr. Sci. Publ. IFAS AE442. 8 Oct. 2014. <http://edis.ifas.ufl.edu/pdffiles/ $\mathrm{AE} / \mathrm{AE} 44200$.pdf $>$.

Dukes, M.D. 2012. Water conservation potential of landscape irrigation smart controllers. Trans. Amer. Soc. Agr. Biol. Eng. 55:563-569.
Dukes, M.D., M. Shedd, and B. Cárdenas-Lailhacar. 2008. Smart irrigation controllers: How do soil moisture sensor (SMS) irrigation controllers work? Univ. Florida, Inst. Food Agr. Sci. Publ. IFAS AE437. 8 Oct. 2014. <http://edis. ifas.ufl.edu/pdffiles/AE/AE43700.pdf>.

Dukes, M.D., M. Shedd, and S.L. Davis. 2009. Smart irrigation controllers: Operation of evapotranspiration-based controllers. Univ. Florida, Inst. Food Agr. Sci. Publ. IFAS AE446. 8 Oct. 2014. <http://edis.ifas.ufl.edu/pdffiles/AE/ AE44600.pdf $>$.

Dunlap, R.E., K.D. Van Liere, A.G. Mertig, and R.E. Jones. 2000. Measuring endorsement of the New Ecological Paradigm: A revised NEP scale. J. Soc. Issues 56:425-442.

Florida Department of Environmental Protection. 2014. Water use trends in Florida: Water resource fact sheet. 17 Sept. 2014. <http://www.dep.state.fl. us/water/waterpolicy/docs/factsheets/ wrfss-water-use-trends.pdf $>$.

Haley, M.B. and M.D. Dukes. 2012. Validation of landscape irrigation reduction with soil moisture sensor irrigation controllers. J. Irrig. Drain. Eng. 138:135-144.

Haley, M.B., M.D. Dukes, and G.L. Miller. 2007. Residential irrigation water use in central Florida. J. Irrig. Drain. Eng. 133:427-434.

Hurd, B.H., R. St. Hilaire, and J.M. White. 2006. Residential landscapes, homeowner attitudes, and water-wise choices in New Mexico. HortTechnology 16:241-246.

Hutson, S.S., N.L. Barber, J.F. Kenny, K.S. Linsey, D.S. Lumia, and M.A. Maupin. 2004. Estimated use of water in the United States in 2000. U.S. Geological Survey Circ. 1268. 17 Sept. 2014. <http://pubs.usgs.gov/circ/2004/ circ1268/pdf/circular1268.pdf>.

Irrigation Association. 2007. Irrigation Association smart water application technologies definition of a smart controller. 18 Sept. 2014. <http://www.irrigation. org/WorkArea/linkit.aspx?LinkIdentifier= id \&ItemID=405\&libID=427>.

Irrigation Association. 2013. Irrigation Association smart water application technologies fact sheet: SWAT testing protocol and EPA WaterSense labeling program. 2 Dec. 2014. <http://www. irrigation.org/uploadedFiles/SWAT/ September\%202013\%20SWAT\%20vs\% 20WaterSense\%20program.pdf>.

Irrigation Association and American Society of Irrigation Consultants. 2014. Landscape irrigation best management practices. 18 Sept. 2014. <http://www. irrigation.org/uploadedFiles/Standards / BMPDesign-Install-Manage.3-18-14\% $282 \% 29$.pdf $>$.

Kenny, J.F., N.L. Barber, S.S. Hutson, K.S. Linsey, J.K. Lovelace, and M.A. Maupin. 2009. Estimated use of water in the United States in 2005. U.S. Geological Survey Circ. 1344. 17 Sept. 2014. <http://pubs.usgs.gov/circ/1344/ pdf/cl344.pdf>.

Marella, R.L. 2014. Water withdrawals, use, and trends in Florida, 2010: U.S. Geological Survey scientific investigations report 2014-5088. 17 Sept. 2014. <http://pubs.usgs.gov/sir/2014/ 5088/pdf/sir2014-5088.pdf $>$.

Maupin, M.A., J.F. Kenny, S.S. Hutson, J.K. Lovelace, N.L. Barber, and K.S. Linsey. 2014. Estimated use of water in the United States in 2010. U.S. Geological Survey Circ. 1405. 10 Apr. 2015. <http://pubs.usgs.gov/circ/1405/ pdf/circl405.pdf>.

Mayer, P.W. and W.B. DeOreo. 2010. Improving urban irrigation efficiency by using weather-based "smart" controllers. J. Amer. Water Works Assn. 102(2):86-97.

Mayer, P.W., W.B. DeOreo, E.M. Opitz, J.C. Kiefer, W.Y. Davis, B. Dziegielewski, and J.O. Nelson. 1999. Residential end uses of water. 2 Dec. 2014. <http:// www.waterrf.org/PublicReportLibrary/ RFR90781_1999_241A.pdf >.

McCready, M.S., M.D. Dukes, and G.L. Miller. 2009. Water conservation potential of smart irrigation controllers on st. augustinegrass. Agr. Water Mgt. 96:1623-1632.

Mutchek, M.A. and E.D. Williams. 2010. Design space characterization for meeting cost and carbon reduction goals: Smart irrigation controllers in the southwestern United States. J. Ind. Ecol. 14:727-739.

Nagelkerke, N.J.D. 1991. A note on a general definition of the coefficient of determination. Biometrika 78:691-692.

Pittenger, D.R., D.A. Shaw, and W.E. Richie. 2004. Evaluation of weathersensing landscape irrigation controllers: A report submitted to Office of Water Use Efficiency, California Department of Water Resources. 2 Dec. 2014. <http:// ucanr.edu/sites/UrbanHort/files / 131533.pdf>.

Romero, C.C., S.L. Davis, and M.D. Dukes. 2011. Smart irrigation controller demonstration and evaluation in Orange County, Florida: Task 2. Univ. Florida, Gainesville.

St. Hilaire, R., M.A. Arnold, D.C. Wilkerson, D.A. Devitt, B.H. Hurd, 
B.J. Lesikar, V.I. Lohr, C.A. Martin, G.V. McDonald, R.L. Morris, D.R. Pittenger, D.A. Shaw, and D.F. Zoldoske. 2008. Efficient water use in residential urban landscapes. HortScience 43:20812092.
St. Johns River Water Management District, South Florida Water Management District, and Southwest Florida Water Management District. 2008. Central Florida Coordination Area: Planning work group final report. 12 Sept. 2014. <https://www.swfwmd.state.fl.us/files/ database/site_file_sets $/ 60 / \mathrm{CFCA}_{-}$ Planning_Group_Final_Report.pdf $>$.

Wolters, E.A. 2014. Attitude-behavior consistency in household water consumption. Soc. Sci. J. 51:455-463. 